\title{
Implementasi Pembelajaran IPA Berbasis STEM Berbantuan ICT untuk Meningkatkan Keterampilan Abad 21
}

\section{The Implementation of Science Based STEM and ICT Learning for Improving The $21^{\text {st }}$ Century Skill}

\author{
Iim Halimatul Mu'minah, M.Pd ${ }^{1 *}$, Ipin Aripin, M.Pd ${ }^{1}$ \\ ${ }^{1}$ Universitas Majalengka1/ Pendidikan Biologi, Universitas Majalengka \\ Received 29 $9^{\text {th }}$ July 2019/ Accepted 20 th August 2019
}

\begin{abstract}
ABSTRAK
Penelitian ini bertujuan untuk mengembangkan pembelajaran berbasis STEM dengan bantuan ICT untuk meningkatkan keterampilan abad 21. Penelitian ini merupakan penelitian Pre-experiment dengan desain penelitian yang digunakan "one group Pretest-posttest design". Sampel terdiri dari 6 kelas dan terpilih satu kelas sebanyak 32 siswa. Pada peningkatan keterampilan berpikir kritis siswa di peroleh skor rata-rata pretest sebesar 69,03 dan skor rata-rata posttest sebesar 82,44 dengan $\mathrm{N}$ Gain sebesar 0,45 dengan kategori sedang. Sedangkan pada peningkatan keterampilan berpikir kreatif siswa diperoleh skor rata-rata pretest sebesar 74,63 dan skor rata-rata posttest sebesar 87,97 dengan N-Gain sebesar 0,56 dengan kategori sedang. Sedangkan Peningkatan keterampilan komunikasi dan kolaborasi diperoleh prosentasi diatas 66\%, keterampilan komunikasi diperoleh hasil sebesar 67,13\% dan keterampilan kolaborasi diperoleh sebesar 74,75\% dan termasuk kategori baik. Tanggapan Siswa diperoleh hasil lebih dari 61\% yaitu sebesar 68,06\% maka termasuk kategori baik pula. Untuk tingkat efektifitas keterlaksanaan pembelajaran diperoleh hasil diatas $61 \%$ yaitu sebesar 72,63\%. Maka dapat disimpulkan Pembelajaran IPA BerbasisScience, Technology, Engineering and Mathematic (STEM)berbantuanICT dapat meningkatkan keterampilan Abad 21 dan berjalan dengan baik.
\end{abstract}

Kata kunci: STEM dengan bantuan ICT, Keterampilan Abad 21, sistem Pencernaan kaitannya dengan zat-zat makanan.

\begin{abstract}
This study aims to develop STEM-based learning with the help of ICT to improve 21 st century skills. This research is a Pre-experiment research with research design used "one group Pretest-posttest design". The sample consisted of 6 classes and 32 students were selected as one class. On the improvement of students' critical thinking skills, the average score of the pretest was 69.03 and the average score of the posttest was 82.44 with an $N$-gain of 0.45 in the medium category. While the improvement of students' creative thinking skills obtained an average pretest score of 74.63 and an
\end{abstract}

*Korespondensi:

email: iimhalimatul1991@gmail.com 
average posttest score of 87.97 with an $\mathrm{N}$-Gain of 0.56 in the medium category. While the improvement of communication and collaboration skills obtained a percentage above $66 \%$, communication skills gained $67.13 \%$ results and collaboration skills obtained by $74.75 \%$ and included in both categories. Student responses obtained results of more than $61 \%$, amounting to $68.06 \%$, including the good category as well. For the effectiveness of the learning outcomes obtained results above $61 \%$ which is $72.63 \%$. So it can be concluded that Science, Technology, Engineering and Mathematic (STEM) Science-Based Learning (ICT) assisted with ICT can improve 21st Century skills and run well.

Keywords: STEM with the help of ICT, 21 st Century Skills, Digestive system related to food substances.

\section{PENDAHULUAN}

Revolusi industri 4.0 yang ditandai dengan munculnya robot-robot pintar yang diprogram secara artificial intelligence (AI) harus disikapi oleh dunia pendidikan untuk melakukan perubahan mendasar pada kurikulum dan proses pembelajarannya agar siswa mampu bersaing di era global. Menurut Bybee, (2010) jika siswa hanya belajar untuk mengingat dan melafalkan kembali pengetahuan dan mempraktikkan keahlian tertentu (pembelajaran tradisional, chalk and talk teaching), dikhawatirkan mereka hanya disiapkan untuk satu jenis pekerjaan yang kenyataannya keahlian-keahlian tertentu tersebut mulai kurang menjual di dunia kerja saat ini.

Tuntutan kerja abad 21 menghendaki pekerja untuk memiliki berbagai keterampilan terkait, seperti berpikir kreatif, pemecahan masalah dan berkomunikasi. Hal ini sebagaimana dinyatakan oleh National Education Association (2012) bahwa jika siswa ingin bersaing di era global maka mereka harus memiliki kemampuan berkomunikasi (Communication), berkolaboras(Collaboration), berpikir kritis (Critical Thinking), dan kreativitas (Creativity) atau dikenal dengan 4C.

Dalam kenyataannya proses pembelajaran yang dilakukan guru di Indonesia belum mengarahkan siswanya untuk mampu berpikir tingkat tinggi yang merupakan tuntutan kerja abad21 sebagaimana tercermin dari hasil PISA tahun 2015 dimana Indonesia berada pada urutan 63 dari 72 negara yang di survey. Hal ini tentunya menjadi tantangan bagi guru IPA untuk melakukan proses pembelajaran yang dapat merangsang siswa untuk mengembangkan kemampuan siswa di bidang sains dan matematika lebih baik lagi.

Penguasaan di bidang eksakta tersebut sebenarnya dapat ditingkatkan melalui pembelajaran yang mengintegrasikan science, technology, engineering and mathematics melalui pembelajaran STEM, yaitu pembelajaran yang mampu memadukan penguasaan konsep akademis dengan pembelajaran dunia nyata yang dapat diaplikasikan dalam kehidupan sehari- hari, dimana peserta didik yang di didik dengan STEM diharapkan mampu memecahkan masalah, menjadi pemikir logis, menguasai teknologi dan dapat mengkaitkan budaya dengan pembelajaran . 
Hal ini diperkuat oleh Bybee (2013) yang menyatakan bahwa STEM dapat membuat siswa belajar mengaplikasikan kandungan utama dan mempraktikan setiap disiplin STEM ke dalam segala situasi yang siswa hadapi dalam hidupnya sehingga terlatih untuk berkomunikasi, berkolaborasi, berpikir tingkat tinggi dan meningkatkan kreativitas sebagaimana tuntutan abad21. Implementasi STEM berbantuan ICT akan lebih mempermudah integrasi STEM dalam pembelajaran IPA. Penelitian tentang penggunaan ICT dalam pembelajaran berbasis STEM telah menunjukkan trend yang positif dimana ICT dapat digunakan sebagai alat tutorial, simulasi virtual dan laboratorium virtual. Selain itu, siswa dan guru dapat menggunakan web untuk berkomunikasi di antara mereka sendiri melalui email, newsgroup dan daftar diskusi, konferensi video untuk komunikasi lokal dan global, dan proyek telekolaboratif . Semua jenis keunggulan yang ditawarkan media berbasi ICT tersebut pada akhirnya dapat membantu guru pada pembelajaran berbasis STEM yang bertujuan melatihkan siswa untuk meningkatkan keterampilan Abad 21. Tujuan umum penelitian ini adalah mengimplementasikan pembelajaran IPA berbasis STEM berbantuan ICT.

Peneliti mengawali penelitian ini dengan melakukan pembelajaran IPA menggunakan media internet pada tahun 2016. Dari penelitian ini diketahui bahwa penggunaan media internet ternyata efektif dalam mengembangkan kemampuan penguasaan konsep pada siswa. Penelitian selanjutnya peneliti lakukan dengan mengimplementasikan pembelajaran berbasis SETS pada pembelajaran IPA, dengan mengkombinasikannya dengan model pembelajaran ternyata mampu mengembangkan penguasaan konsep dan pemahaman tentang sains dan teknologi pada siswa. Melalui penelitian yang akan dilakukan pada tahun 2019 ini peneliti ingin mengembangkan penelitian berbasis STEM berbantuan ICT (information, communication and technology) terhadap keterampilan Abad 21 pada siswa menengah pertama. Hal ini didasari oleh rendahnya keterampilan Abad 21 siswa terutama dalam aspek kemampuan berpikir tingkat tinggi dan kreativitas.

Penggunaan pembelajaran berbasis STEM (Science, Technology, Engineering, andMathematics) merupakan alternatif yang cocok mengingat tuntutan dunia kerja Abad 21 menghendaki siswa untuk menguasai bidang sains, teknologi, teknik dan matematika sehingga melalui pendidikan berbasis STEM berperan penting dalam keberhasilan siswa di masa mendatang. Menurut Rustaman (2015) pendidikan berbasis STEM merupakan integrasi antara sains, teknologi, teknik dan matematika ke dalam satu trans-disiplin baru di sekolah .

Sejalan dengan pendapat Rustaman (2005), Reeve (2013:8) mendefinisikan STEM sebagai pendekatan interdisiplin pada pembelajaran, yang mana siswa mengimplementasikan sains, teknologi, teknik dan matematika dalam kontek nyata yang mengkoneksikan sekolah, dunia kerja, dan masyarakat global untuk mengembangkan STEM pada siswa. Beers (2011) mengungkapkan bahwa STEM merupakan integrasi keilmuan antara sains, teknologi, teknik, dan matematika yang dapat menjadi kunci sukses siswa pada Abad 21 [10]. STEM Education disediakan untuk mencapai tujuan pendidikan yang mempersiapkan orang untuk kehidupan masa 
depan dan tenaga kerja. Integrasi dan aplikasi konsep dan proses S-T-E-M diperlukan oleh semua, dan orang muda harus memiliki kesempatan berpartisipasi dalam situasi multidisipliner nyata. Menurut Hoeg (2016) pendidikan STEM sangat penting dalam pengembangan ekonomi dan termuat dalam dokumen-dokumen NGSS (Next Generation Science Standar) Negara-negara bagian di Amerika.

\section{METODE}

Metode penelitian yang digunakan dalam penelitian ini adalah pre-experiment, yaitu penelitian yang tidak menggunakan kelompok kontrol sebagai pembanding perlakuan dan sampel tidak dipilih secara random.

Desain penelitian yang digunakan adalah the one-grup pretest-posttest design. Pada rancanganini kelas yang dijadikan objek penelitian diukur sebelum dan sesudah diberikan treatment (perlakuan). Siswa diberitesawal berupates (berpikir kritis dan teskreativitas) untuk mengetahui kemampuan awal siswa dalam berpikir kritis dan keterampilan berpikir kreatifpada konsep sistem Pencernaan kaitannya dengan zat-zat makanan, selanjutnya siswa diberi perlakuan dengan menggunakan STEM dengan bantuan ICT. Siswa juga dinilai kinerjanya untuk menganalisis keterampilan komunikasi dan kolaborasi selama proses pembelajaran.Untuk mengidentifikasi pengaruh perlakuan berupa peningkatan keterampilan abad 21 siswa, maka dilakukan tes akhir.

Penelitian ini dilaksanakan di MTs Negeri 2 Majalengka Kabupaten Majalengka. Sekolah ini dipilih karena merupakan sekolah dibawah DepartemenAgama yang telah mengimplementasikan Kurikulum 2013 revisidi Kabupaten Majalengka. Selainitu, memiliki fasilitas serta sarana dan prasana pembelajaran yang mendukung bagi penelitian ini. Subjek dalam penelitian ini adalah siswa kelas VIII (delapan) semester ganjil tahun ajaran 2019/2020 sebanyak satu kelas,dengan teknik sampling menggunakan purposive sampling(sampling bertujuan) berdasarkan pertimbangan guru IPA yang mengajar di sekolah tersebut.

\section{HASIL DAN PEMBAHASAN}

Peningkatan Keterampilan Berpikir Kritis dengan Pembelajaran Berbasis Science, Technology, Engineering and Mathematic (STEM) berbantuan ICT pada Konsep Sistem Pencernaan Kaitannya dengan Zat-zat makanan

Peningkatan keterampilan berpikir kritis siswa pada konsep materi Sistem pencernaan kaitannya dengan zat-zat makanan diperoleh dari selisih skor pretest dan posttest selama pembelajaran. Skor maksimal keterampilan berpikir kritis siswa adalah 100. Hasil dapat dilihat pada Tabel 1 berikut.

Tabel 1. Peningkatan Keterampilan Berpikir Kritis Siswa

\begin{tabular}{cccc}
\hline Rata-rata Pretest & Rata-rata Posttest & N-Gain & Kategori \\
\hline 69,03 & 82,44 & 0,45 & Sedang \\
\hline
\end{tabular}


Berdasarkan Tabel 1 diatas dapat diketahui bahwa terjadi peningkatan keterampilan berpikir kritis siswa pada kelas tersebut. Skor rata-rata pretest sebesar 69,03. Berdasarkan Arikunto (2002:245) nilai tersebut termasuk kategori kurang[11]. Namun, setelah pembelajaran Berbasis Science, Technology, Engineering and Mathematic (STEM) berbantuan ICT pada konsep materi sistem pencernaan katiannya dengan zat-zat makanan, skor rata-rata keterampilan berpikir kritis siswa menjadi 82,44. Oleh karena itu, dapat dikatakan bahwa pada kelasa tersebut, keterampilan berpikir kritis posttest lebih baik dari pretest dan menunjukan hasil yang cukup tinggi. Disamping hal itu, apabila dilihat berdasarkan Kriteria Ketuntasan Minimal (KKM) yang telah ditetapkan sebesar 70,00. Maka hasil belajar siswa setelah pembelajaran Berbasis Science, Technology, Engineering and Mathematic (STEM) berbantuan ICT sudah terpenuhi dan berada diatas standar ketuntasan minimalnya. Maka pembelajaran Berbasis Science, Technology, Engineering and Mathematic (STEM) berbantuan ICT ini sudah berhasil dan dapat meningkatkan hasil belajar IPA pada konsep materi sistem pencernaan katiannya dengan zat-zat makanan.

Tabel 1 pun menunjukan skor N-Gain sebesar 0,45. Secara keseluruhan berdasarkan kategori menurut (Meltzer, 2002) maka kelas sampel tersebut keterampilan berpikir kritisnya berada pada kategori sedang[12]. Artinya dari kedua belas sub indikator keterampilan berpikir kritis ini, siswa sudah mampu mengusasai sepuluh sub indikator yaitu Memfokuskan Pertanyaan, Menganalisis argumen, Bertanya dan menjawab pertanyaan tentang suatu penjelasan atau gagasan, Mengobservasi dan menilai laporan hasil observasi, Menilai hasil deduksi, Membuat dan mempertimbangkan keputusan, Mendefinisikan istilah dan mempertimbangkan definisi, Mengidentifikasi asumsi, Memutuskan suatu tindakan, Berinteraksi dengan orang lain, dilihat dari hasil pretest dan posttest yang sangat signifikan sbelum dan sesudah pembelajaran dengan pembelajaran Berbasis Science, Technology, Engineering and Mathematic (STEM) berbantuan ICT ini sudah berhasil dan dapat meningkatkan hasil belajar IPA pada konsep materi sistem pencernaan katiannya dengan zat-zat makanan. Berdasarkan hasil pengujian keterampilan berpikir kritis melalui Paired sample T-Test memperlihatkan bahwa terdapat peningkatan keterampilan berpikir kritis siswa yang signifikan pada siswa setelah implementasi pembelajaran pembelajaran Berbasis Science, Technology, Engineering and Mathematic (STEM) berbantuan ICT pada konsep materi Sistem pencernaan dan kaitannya dengan zat-zat makanan.

\section{Peningkatan Keterampilan Berpikir Kreatif dengan Pembelajaran Berbasis Science, Technology, Engineering and Mathematic (STEM) berbantuan ICT pada Konsep Sistem Pencernaan Kaitannya dengan Zat-zat makanan}

Keterampilan berpikir kreatif yang diukur dalam penelitian ini menurut munandar (Sumarmo 2013:481) meliputi Berpikir lancar (Fluency), Berpikir Luwes (Flexibility),Berpikir Original (Originality) dan Berpikir Elaboratif (Elaboration)[13]. Peningkatan Keterampilan berpikir kreatif pada kelas sampel diperoleh dari selisih skor sebelum dan sesudah Pembelajaran Berbasis Science, Technology, Engineering and 
Mathematic (STEM) berbantuan ICT pada Konsep Sistem Pencernaan Kaitannya dengan Zat-zat makanan. Skor rata-rata sebelum dan sesudah pembelajaran pada kelas tersebut, skor maksimalnya adalah 100. Data selengkapnya dapat dilihat pada Tabel 2.

Tabel 2. Peningkatan Keterampilan Berpikir Kreatif

\begin{tabular}{cccc}
\hline Rata-rata Pretest & Rata-rata Posttest & N-Gain & Kategori \\
\hline 74,63 & 87,97 & 0,56 & Sedang \\
\hline
\end{tabular}

Berdasarkan Tabel 2 dapat diketahui bahwa terjadi peningkatan keterampilan berpikir kreatif siswa. Skor rata-rata awal keterampilan berpikir kreatif sebesar 74,63 dan setelah pembelajaran melalui pembelajaran Berbasis Science, Technology, Engineering and Mathematic (STEM) berbantuan ICT pada konsep materi sistem pencernaan kaitannya dengan zat-zat makanan, skor rata-rata akhir keterampilan berpikir kreatif siswa sebesar 87,97. Berdasarkan data tersebut, menunjukan bahwa keterampilan berpikir kreatif siswa akhir lebih baik dari keterampilan berpikir kreatif siswa awal. Disamping hal itu, apabila dilihat berdasarkan Kriteria Ketuntasan Minimal (KKM) yang telah ditetapkan, maka hasil belajar siswa setelah pembelajaran melalui pembelajaran Berbasis Science, Technology, Engineering and Mathematic (STEM) berbantuan ICT pada konsep materi sistem pencernaan kaitannya dengan zat-zat makanan sudah terpenuhi dan berada diatas standar ketuntasan minimalnya.

Tabel 2 menunjukan skor N-Gain pada kelas sampel sebesar 0,56. Berdasarkan kategorisasi menurut (Meltzer,2002), maka kelas sampel tersebut mengalami peningkatan keterampilan berpikir kreatif siswa dengan kategori sedang. Artinya dari keempat aspek keterampilan berpikir kreatif siswa ini, siswa sudah mampu menguasai tiga aspek keterampilan berpikir kreatif siswa yaitu Berpikir lancar (Fluency), Berpikir Luwes (Flexibility), dan Berpikir Elaboratif (Elaboration) dilihat dari peningkatan hasil pretest dan posttest yang sangat signifikan sebelum pembelajaran dan sesudah pembelajaran dengan melalui pembelajaran Berbasis Science, Technology, Engineering and Mathematic (STEM) berbantuan ICT pada konsep materi sistem pencernaan kaitannya dengan zat-zat makanan. Berdasarkan hasil pengujian hipotesis keterampilan berpikir kreatif siswa melalui Paired Sample T-test pada kelas tersebut menunjukan bahwa terdapat peningkatan keterampilan berpikir kreatif siswa yang signifikan pada siswa setelah pembelajaran Berbasis Science, Technology, Engineering and Mathematic (STEM) berbantuan ICT pada konsep materi sistem pencernaan kaitannya dengan zatzat makanan.

Sedangkan Peningkatan keterampilan komunikasi dan kolaborasi diperoleh prosentasi diatas 66\%, keterampilan komunikasi diperoleh hasil sebesar 67,13\% dan keterampilan kolaborasi diperoleh sebesar $74,75 \%$ dan termasuk kategori baik. Tanggapan Siswa diperoleh hasil lebih dari 61\% yaitu sebesar 68,06\% maka termasuk kategori baik pula. Untuk tingkat efektifitas keterlaksanaan pembelajaran diperoleh hasil diatas $61 \%$ yaitu sebesar $72,63 \%$.

Peningkatan keterampilan komunikasi dan kolaborasi diperoleh prosentasi diatas $66 \%$, keterampilan komunikasi diperoleh hasil sebesar $67,13 \%$ dan keterampilan 
kolaborasi diperoleh sebesar 74,75\% dan termasuk kategori baik. Tanggapan Siswa diperoleh hasil lebih dari $61 \%$ yaitu sebesar $68,06 \%$ maka termasuk kategori baik pula. Untuk tingkat efektifitas keterlaksanaan pembelajaran diperoleh hasil diatas $61 \%$ yaitu sebesar $72,63 \%$.

\section{KESIMPULAN}

Berdasarkan penelitian yang telah di lakukan maka kesimpulan pada penelitian ini adalah Pembelajaran IPA Berbasis Science, Technology, Engineering and Mathematic (STEM) berbantuan ICTdapat meningkatkan keterampilan Abad 21 dan berjalan dengan baik. penerapan Pembelajaran IPA berbasis Berbasis Science, Technology, Engineering and Mathematic (STEM) berbantuan ICT dapat meningkatkan keterampilan Abad 21 Secara signifikan. Peningkatan keterampilan berpikir kritis siswa dapat diketahui melalui skor rata-rata siswa sebelum pemeblajaran sebesar 69,03 dan setelah pembelajaran sebesar 82,44. Hal ini menunjukan adanya peningkatan keterampilan berpikir kritis siswa sebelum dan sesudah pembelajaran Berbasis Science, Technology, Engineering and Mathematic (STEM) berbantuan ICT. Rata-rata nilai N-Gain 0,45 dan berada pada kategori sedang. Peningkatan keterampilan berpikir kreatif siswa dapat dikaetahui melalui skor rata-rata siswa sebelum pembelajaran sebesar 74,63 lebih kecil dibandingkan skor rata-rata siswa setelah pembelajaran sebesar 87,97. Hal ini menunjukan adanya peningkatanmketerampilan berpiki kreatif siswa sebelum dan sesudah pembelajaran dengan menggunakanPembelajaran IPA Berbasis Science, Technology, Engineering and Mathematic (STEM) berbantuan ICT. Rata-rata nilai NGain 0,56 dan berada pada kategori sedang. Sedangkan Peningkatan keterampilan komunikasi dan kolaborasi diperoleh prosentasi diatas 66\%, keterampilan komunikasi diperoleh hasil sebesar $67,13 \%$ dan keterampilan kolaborasi diperoleh sebesar 74,75\% dan termasuk kategori baik. Tanggapan Siswa diperoleh hasil lebih dari $61 \%$ yaitu sebesar 68,06\% maka termasuk kategori baik pula. Untuk tingkat efektifitas keterlaksanaan pembelajaran diperoleh hasil diatas $61 \%$ yaitu sebesar $72,63 \%$.

\section{DAFTAR PUSTAKA}

National Education Association. (2012). Preparing $21^{\text {st }}$ Century Students for A Global Society.

OECD. (2015). PISA Result and Focus. OECD. www.oecd.org/pisa

Gallant, D. J. (2010). Science, Technology, Engineering, and Mathematics (STEM) Education. Ohio State University

Bybee, R.W. (2013). The Case for STEM Education-Challenges and Opportunities. Virginia: NSTA Press. 
Stohlmann, M., Moore, T. J., Mc Clelland, J., \& Roehrig, G.H. (2011). Impressions of a middle grades STEM integration program. Middle School Journal, 43(1), 3240 .

Rustaman,N.Y. (2015). STEM EDUCATION: How to integrate STEM Education into Biology subject-matter?. Disampaikan pada Seminar Nasional Universitas Negeri Yogyakarta (UNY).

Beer, S. Z. (2011). 21 st Century Skills: Preparing Students for THEIR Future.

Reeve, E.M. (2013). Implementing Science, Technology, Mathematics, and Engineering (STEM) Education in Thailand and in ASEAN. USA: Utah State University.

Sugiono.(2010). Metode Penelitian Pendidikan Pendekatan Kuantitatif,Kualitatif, dan $R \& D$. Bandung: Alfabeta.

Arikunto, S. (2012). Dasar-Dasar Evaluasi Pendidikan. Jakarta: Bumi Aksara.

Arikunto, S. (2002). Prosedur Penelitian. Jakarta: PT Rineka Cipta.

Meltzer, D.E. (2002). The relationship between Mathematics Prepation and Conceptual Learning Gain in Physics:A posible "Hiden Variable" in Diagnostic Pretes Score. American Journal Physics, 70 (12), hlm. 1259-1268.

Sumarmo, U. (2013). Berpikir dan Disposisi matematik serta pembelajarannya. Bandung: Jurdik matematika FPMIPA UPI.

Kurniawan, Haviz. (2018). Implementasi Pembelajaran IPA Berbasis STEM untuk meningkatkan Kemmapuan Komunikasi siswa. Simposium Nasional 2018,140.

Muharomah, Dewi Robiatun. (2017). Pengaruh Pembelajaran STEM (Science, Technology, Engineering, And Mathematics) Terhadap Hasil Belajar Peserta didik pada Konsep Evolusi. Skripsi. UIN Syarif Hidayatullah, Jakarta 